\title{
Potential Adverse and Allergic Reactions from Complementary and Alternative Medicine and Dietary Supplements
}

\author{
H.C. George Wong, MD, FRCPC, FACP, FAAAAI, FCCP
}

\begin{abstract}
Complementary and alternative medicine and dietary supplements are often used by patients. A detailed examination of each preparation used by four patients was carried out. Seven such preparations with the potential to cause bleeding, cardiovascular and central nervous system side effects, and allergic food reactions are described. They were taken by both Asian and Caucasian patients, were purchased locally, and were used for allergic and nonallergic disorders. Inquiry into their use is important to prevent potential adverse and allergic reactions. There should be a higher standard of regulation for such products.
\end{abstract}

Complementary and alternative medicine (CAM) preparations and dietary supplement (DS) products are frequently used by patients without the knowledge of their physicians. Such preparations can be purchased from local health food stores, Chinese herbal shops, pharmacies, and Internet sites, ${ }^{1}$ or they can be brought in from elsewhere. ${ }^{2}$ This article describes seven preparations used by four patients for allergic and nonallergic disorders and identified during inquiry into the use of CAM and DS products as part of obtaining histories.

H.C.G. Wong - Clinical Professor, University of British Columbia, British Columbia; Vancouver General Hospital, Vancouver, British Columbia

Correspondence to: Dr. H.C. George Wong, 750 West Broadway, Suite 1200, Vancouver, BC V5Z 1J2; e-mail: hcgwong@telus.net

Some of the information contained in this article was presented at the Canadian Society of Allergy and Clinical Immunology 2001 Annual Scientific Meeting, October 26 to 28,2001 , Banff, $\mathrm{AB}$.

DOI $10.2310 / 7480.2006 .00007$

\section{Case Histories}

A 59-year-old Vietnamese woman with chronic urticaria reported the use of two CAM preparations: Kwan Loong Oil (containing methyl salicylate) and Zhui Feng So Hop Wan (pills with unknown content).

A 68-year-old Chinese woman with allergic rhinitis was taking a Chinese patent medicine, Dan Shen Pill (containing radix Salvia miltiorrhiza), for her coronary artery disease.

A 34-year-old Caucasian man with allergic rhinitis and asthma had been taking ClearLungs Chinese Formula For The Lungs (capsules containing licorice root and other herbal and food components) and YOUR CHOICE - SPORTS 52 EPHEDRINE-HCL (30 mg capsules).

A 30-year-old Caucasian man with a food anaphylaxis to mustard (confirmed by positivity on skin-prick testing) recently started taking two DS products: (1) LifePak Dietary Supplement, a vitamin/phytonutrient capsule with extracts of grape, tomato, broccoli, and alfalfa, and (2) Natural Factors Acidophilus \& Bifidus capsules, containing a base of whey and powdered goat milk. 
The two Asian patients obtained the three CAM products from local Chinese herbal shops whereas the two Caucasian patients used CAM and DS products purchased from health food stores.

None of the patients manifested specific adverse or allergic reactions to these CAM preparations and DS products. However, the potential for reactions was discussed with the patients and was reported to the referring family physicians.

\section{Complementary and Alternative Medicine and Dietary Supplement Products Used by the Patients}

A summary of the CAM and DS products discussed below and their potential side effects is presented in Table 1.

\section{Kwan Loong Oil}

Kwan Loong Oil, a muscle pain-relieving aromatic oil, was made by Drug Houses of Australia (Asia) Pte Ltd, Singapore, for Tiger Minerals Ltd, under license from Haw Par Brothers International (H.K.) Ltd. It was imported by Le Kiu Importing Co. Ltd., Vancouver, BC, and Wellbond Import Export Inc., Scarborough, ON.

The active ingredients included methyl salicylate $28 \%$ weight per weight $(\mathrm{w} / \mathrm{w})$, methol $16 \% \mathrm{w} / \mathrm{w}$, and eucalyptus oil $3 \% \mathrm{w} / \mathrm{w}$. A warning on the bottle's label included, "(1) keep out of reach of children, and (2) do not use this product if you are allergic to salicylates or if you are taking anticoagulant medications (warfarin for example)."

\section{Zhui Feng So Hop Wan}

Zhui Feng So Hop Wan (Pill) was manufactured by Hong Kong Lee Chan Ji Pharmaceutical Company Limited. According to the Chinese-only accompanying insert, "the preparation was of herbal origin, based on a traditional family formula of 300 years' history and on sale in Southeast Asia and North America, and South America for over 70 years. Indications included flu, rhinitis, cough, vomiting, abdominal distention, dizziness, children sickness, and postpartum illnesses. It could be used for emergencies, but its use during pregnancy was contraindicated." The authentication of the product was emphasized. Individual Chinese herbs were not identified.

\section{Dan Shen Pill}

Compound Dan Shen Pill (Danshenpian [Salvia miltiorrhiza] Compound), was a product of Guangdong Pharmaceutical Factory, Kwangtong, China. It came with an insert in both Chinese and English, which stated the following: "The Compound was tested in over 400 cases in clinical observation on coronary heart disease patients conducted by the clinical units of Guangdong, Shanghai, Zhejing, Jiangsu and Auhui, etc. Its angina pectoris efficacy ratio was $34.7 \%$, total efficacy ratio $85.6 \%$, electrocardiogram efficacy ratio $20.1 \%$, and a total efficacy $58.1 \%$. The clinical practice had shown that the Compound/Pill can alleviate conditions of myoischemia (insufficiency of blood supply to cardiac muscle), insufficiency of oxygen supply to cardiac muscle and myocardial anabolism. No side effects had been found with the few exceptions of occasional uncomfortable feeling in the stomach."

Each tablet consisted of pseudo-ginseng $22.5 \%$, denshen (Salvia miltiorrhiza) $75 \%$, and borneo $2.5 \%$. According to the insert, "The functions included activating blood circulation to dissipate blood stasis, aromatic therapy for waking up a patient from unconsciousness and regulating vital energy and alleviating pain. The indications included for curing coronary diseases and used in such syndromes as feeling oppression in the chest and angina pectoris (breast pang sic), etc.” There was no expiry date or lot number.

\section{ClearLungs Chinese Formula For The Lungs}

ClearLungs Chinese Formula For The Lungs was a herbal supplement. It was manufactured by Ridgecrest Herbals, Inc., Salt Lake City, UT. Listed under the section on supplement facts, the 
Table 1 Summary of Complementary and Alternative Medicine and Dietary Supplement Products and Their Potential Side Effects

\begin{tabular}{|c|c|c|}
\hline Product & Major Component(s) of Concern & Potential Side Effects \\
\hline $\begin{array}{l}\text { Kwan Loong Oil } \\
\text { Zhui Feng So } \\
\text { Hop Wan (Pill) }\end{array}$ & $\begin{array}{l}\text { Methyl salicylate } \\
\text { (Unknown content) }\end{array}$ & $\begin{array}{l}\text { Bleeding in patients taking anticoagulant } \\
\text { Herb-drug interaction }\end{array}$ \\
\hline Dan Shen Pill & Radix Salvia miltiorrhiza & Bleeding in patients taking anticoagulant \\
\hline $\begin{array}{l}\text { ClearLungs Chinese } \\
\text { Formula For The Lungs }\end{array}$ & $\begin{array}{l}\text { Licorice root with other herbal and } \\
\text { food components }\end{array}$ & Hypertension, hypokalemia \\
\hline $\begin{array}{l}\text { YOUR CHOICE-SPORTS } \\
52 \text { EPHEDRINE-HCL } \\
\text { (30 mg capsules) }\end{array}$ & Ephedrine & $\begin{array}{l}\text { Cardiovascular/central nervous } \\
\text { system complications }\end{array}$ \\
\hline LifePak Dietary Supplement & Some food extracts & $\begin{array}{l}\text { Adverse reaction in patients with } \\
\text { specific food allergy }\end{array}$ \\
\hline $\begin{array}{l}\text { Natural Factors Acidophilus } \\
\text { \& Bifidus Capsule }\end{array}$ & Whey, powdered goat milk & $\begin{array}{l}\text { Adverse reaction in patients with } \\
\text { specific food allergy }\end{array}$ \\
\hline
\end{tabular}

ingredients included "Dong-Quai Root, Polyporus (Hoelen) fungal body, Ophiopogon (Ophiopogon ohwii Okoyama) root, Almond (Amygdalus prunus) seed, Asparagus (Asparagus officinalis) tips, Citrus rind (Chen-Pi), Chekiang Fritillary bulb, Gardenia Fruits (fruit), White Mulberry (Morus) leaf, Balloon-Flower (Platycodon) root, Biakal Skullcap (Scute) root, Schisandra fruit and Chinese Licorice root." It was supposed to list the percentage of the daily value of the individual herbs but stated, "daily value not established."

The label stated, "ClearLungs $\mathrm{s}^{\mathrm{TM}}$ being a unique Chinese herbal formula designed to help maintain healthy lungs and Chinese herbs had been used successfully for hundreds of years throughout Asia." It was accompanied by a testimonial ("The results with ClearLungs are like a miracle. I don't want to be without it." A.B. Washington.) There was no expiry date.

\section{YOUR CHOICE - SPORTS 52 EPHEDRINE $-H C L$}

YOUR CHOICE - SPORTS 52 EPHEDRINE HCL was manufactured for YOUR CHOICE, Scottsdale, AZ. Each capsule contained ephedrine $\mathrm{HCl} 30 \mathrm{mg}$, without wheat, corn, dairy, soy, yeast, or any other filler. The direction was to "take one capsule 30 minutes before exercise, or as directed by health care professional."
Warnings included the following: "Ephedrine is a CNS (Central Nervous System) stimulator, do not use if receiving MAO inhibitors, prone to hypertension, hyperthyroidism or presence of coronary thrombosis"; "The amino acid L-tyrosine can be use in conjunction with ephedrine"; "Tyrosine has shown to increase the effects of ephedrine by up to $50 \%$ and by combining these two products, sensitive person could cut in half their ephedrine dosage"; and "There was no animal testing done on this product."

\section{LifePak Dietary Supplement}

LifePak Dietary Supplement was manufactured in the United States exclusively for Pharmanex, a division of Nu Skin Enterprises, Inc., by Natural Alternatives International, San Marcos, CA, and distributed by Nu Skin Hong Kong, Inc. It was packaged in packets, each containing one vita$\mathrm{min}$ /phytonutrient capsule and two mineral capsules. The recommended adult dose was two packets daily, hence two vitamin/phytonutrient capsules and four mineral capsules daily.

As labelled, the active ingredients in the two vitamin/phytonutrient capsules were "Vitamin C (Calcium Ascorbate Complex-Ester-C) $500 \mathrm{mg}$, Vitamin E (d-Alpha Tocopheryl Succinate, Beta, Gamma, Delta Tocopherols) 300 I.U., Vitamin A (Beta Carotene, Vitamin A Palmitate, Dunaliella 
Salina) 9000 I.U., Niacin (Niacinamide) $40 \mathrm{mg}$, Grape Skin Extract with Polyphenols (Anthocyanins) $44 \mathrm{mg}$, Acerola Cherry Extract $32 \mathrm{mg}$., Biotin (Biotin) $300 \mathrm{mg}$, Pantothenic Acid (dCalcium Pantothenate) $20 \mathrm{mg}$, Freeze Dried Tomato Powder with Lycopene $20 \mathrm{mg}$, Powdered Broccoli Extract with Sulfuraphane $16 \mathrm{mg}$, Vitamin B6 (Pyridoxine Hydrochloride, Pyridoxal-5Phosphate) $4 \mathrm{mg}$, Vitamin D3 (Cholecalciferol) 400 I.U., Vitamin B2 (Riboflavin, Riboflavin-5Phosphate) $3.4 \mathrm{mg}$, Vitamin B1 (Thiamine Mononitrate) $3 \mathrm{mg}$, Bilberry Powder with Anthocyanosides $4 \mathrm{mg}$, Leucoanthocyanin (Grape Seed Extract) $2 \mathrm{mg}$, Alfalfa Extract with Lutein $2 \mathrm{mg}$, Vitamin B12 (Cyanocobalamin, Dibencozide) $12 \mathrm{mcg}$, Reduced Glutathione $1 \mathrm{mg}$, and Folic Acid (Folacin) $400 \mathrm{mcg}$ ". The inactive ingredients included gelatin cellulose, magnesium stearate, and carboxymethyl cellulose.

As labelled, the active ingredients in the four mineral capsules were "Calcium (Calcium Carbonate, Calcium Citrate, Calcium Chelate) $500 \mathrm{mg}$, Magnesium (Magnesium Chelate, Magnesium Citrate, Magnesium Oxide) $200 \mathrm{mg}$, Carnitine (ICarnitine I-Tartrate) $150 \mathrm{mg}$, Copper (Copper Chelate) $2 \mathrm{mg}$, Zinc (Zinc Chelate) $150 \mathrm{mg}$, Iron (Iron Chelate) $6 \mathrm{mg}$, Manganese (Manganese Chelate) $3.5 \mathrm{mg}$, Boron (Boron Citrate) $1 \mathrm{mg}$, Selenium (I-Selenomethionine) $100 \mathrm{mcg}$, Chromium (Chromium Chelate, Chromium Picolinate), $200 \mathrm{mcg}$, and Iodine (Potassium Iodide) 75 mcg." The inactive ingredients included gelatin, cellulose, carboxymethylcellulose, magnesium stearate, and maltodextrin.

The instructions pointed out that pregnant or lactating women and people with known medical conditions should consult with a physician prior to taking supplements. There was a guarantee that the product contained no added sugar, salt, wheat, yeast, or dairy products and no preservatives, artificial colours, or flavours.

\section{Natural Factors Acidophilus \& Bifidus}

Natural Factors Acidophilus \& Bifidus Capsule (double-strength capsules) a probiotic formula, was manufactured by Natural Factors, Burnaby,
BC. Each capsule contained 10 billion active cells of specially cultured strains of probiotics, including Lactobacillus rhamnosus $80 \%$ (8 billion live cells), Lactobacillus acidophilus 10\% (1 billion live cells), and Bifidobacterium bifidum 10\% (1 billion live cells). These microorganisms were in a base of lactose, whey, powdered goat milk, magnesium stearate (used as a lubricant), pectin, and ascorbic acid, all in a gelatin capsule. The product contained no artifical preservatives, colour, corn, gluten, soya, starch, sweeteners, or yeast.

\section{Discussion}

The first patient used two CAM products for her chronic urticaria. Kwan Loong Oil contained 28\% methyl salicylate, and its instructions warned of interaction with the anticoagulant effect of warfarin. Methyl salicylate can be absorbed through the skin, being more lipid soluble than is aspirin or salicylic acid. Ten millilitres of the $28 \%$ methyl salicylate medicated oil contain the salicylate equivalent of thirteen $300 \mathrm{mg}$ aspirin tablets. Hence, it may cause bleeding when used with warfarin. ${ }^{3,4}$

It is not uncommon to have preparations whose herbal content is unknown, as with Zhui Feng So Hop Wan (Pill). ${ }^{5}$ There is a potential for herbdrug interaction. In addition, some Chinese patent medicines may contain pharmaceutical products ${ }^{6}$ and prescription drugs. ${ }^{7,8}$

Dan Shen Pill, containing radix Salvia miltiorrhiza, was used by the second patient. In traditional Chinese medicine, Dan Shen, the dried root of Salvia miltiorrhiza Bge. (Labiatac), is used for coronary artery disease. ${ }^{9}$ As with the case of the methyl salicylate medicated oil, a warfarin-Dan Shen interaction has been well documented.$^{3,10,11}$ A recent randomized controlled trial showed that American ginseng reduces warfarin's effect in healthy patients. ${ }^{12}$ However, Dan Shen Pill claimed to have no side effects. Its insert described the results of a clinical study but was not entirely clear. This preparation was used by the patient for coronary artery disease and not for the allergic rhinitis for which she had been referred. 
ClearLungs Chinese Formula for the Lungs and YOUR CHOICE - SPORTS 52 EPHEDRINE - HCL (30 mg) capsules were used by the third patient for allergic rhinitis and asthma. The composition of the first preparation included Chinese licorice root containing glycyrrhizin and glycyrrhetinic acid with mineralocorticoid activity. ${ }^{13}$ Hypertensive crisis and hypokalemia from Chinese patent medicine containing licorice has been documented. ${ }^{14}$

The adverse cardiovascular and central nervous system side effects from ephedra/ephedrine are well known..$^{15}$ The $30 \mathrm{mg}$ dosage of the EPHEDRINE-HCL capsule exceeded that outlined by the US Food and Drug Administration's 1997 proposal. ${ }^{16}$ Health Canada issued a voluntary recall of certain products containing ephedra/ephedrine. ${ }^{17}$ The following resolution was proposed by the author through the Alternative Therapies and Allied Health Committee: "ephedra/ephedrine-be it resolved that the board of British Columbia Medical Association (BCMA) make representation to the provincial and federal health authorities to make the recent voluntary recall by Health Canada on certain natural health products containing ephedra/ephedrine compulsory." ${ }^{18}$ It was passed during the annual meeting of BCMA on June 15, 2002.

At present, avoidance remains the number-one approach in the management of food anaphylaxis, along with epinephrine auto-injectors (EpiPen, Twinject) and antihistamines for emergency use. Careful reading of food labels is very important. The two DS products (the LifePak Dietary Supplement vitamin/phytonutrient capsules and the Natural Factors Acidophilus \& Bifidus capsules) used by the fourth patient, who had food anaphylaxis, contain food products. Mustard anaphylaxis, as seen in this patient, is uncommon. ${ }^{19}$ Mustard is not among the food products listed as included in these two DS preparations. On the other hand, patients with the more common dairy product allergy, for example, may be in trouble with the second preparation, which contains whey.

The CAM product ClearLungs Chinese Formula For The Lungs capsules used by the third patient contains food products in addition to herbal components.
Besides the reading of food labels, diligent examination of the contents of both CAM and DS products is important for patients with food anaphylaxis or who experience adverse food reactions.

In the United States, natural/herbal health products are classified as dietary supplements under the Dietary Supplement Health and Education Act of $1994 . .^{20}$ They are not subject to the stringent regulation of the US Food and Drug Administration. There is relatively better regulation of these products under the Natural Health Products Directorate in Canada.

All seven preparations discussed in this article were purchased in local Chinese herbal shops and health food stores. The Natural Health Products Directorate should provide and enforce higher standards of regulation. The BCMA resolution in 2002 noted above was to raise such standards in one specific area.

In summary, seven CAM and DS products were used by four patients, Asian and Caucasian. The products were purchased locally and were used for allergic and other disorders. They included one preparation of unknown content and two preparations with a known herb-drug interaction causing bleeding complications (also of concern to surgical colleagues). Other preparations contained ephedrine and Chinese herbs with potential cardiovascular and other side effects and food substances with the potential to cause allergic food reactions.

\section{Conclusion}

Physicians should inquire about their patients' use of CAM and DS products and should document the contents of such products diligently. Patients are to be advised to read labels and inserts carefully, especially if they have a food or drug allergy or an underlying illness, and to report the use of these products to their doctors. Potential adverse and allergic reactions and herb-drug interactions from CAM and DS products can be identified and avoided. There should be higher regulation of natural health products in British Columbia and in the rest of Canada. 


\section{Acknowledgements}

The author would like to thank the Library of the College of Physicians and Surgeons of British Columbia for the literature research and Ms. S. Hasham for secretarial aid.

\section{References}

1. Morris CA, Avorn J. Internet marketing of herbal products. JAMA 2003;290:1505-20.

2. Wong HCG. Chinese herbal medicine and allergy. Allergy Clin Immunol Int: J World Allergy Org 2001;13:192-6.

3. Yip ASB, Chow WH, Tai YT, Cheung KL. Adverse effect of tropical methylsalicylate ointment on warfarin anticoagulant: an unrecognized potential hazard. Postgrad Med J 1990;66:367-9.

4. Tam LS, Chan TYK, Leung WK, Critchley JAJH. Warfarin interactions with Chinese traditional medicine: danshen and methyl salicylate medicated oil. Aust N Z J Med 1995;25:258.

5. Wong HCG. Chinese patent medicine (Zhong Cheng Yao) of herbal and unknown origin used in allergic and other conditions. Can J Allergy Immunol 2001;6:162-5.

6. Wong HCG. Potential adverse reaction from complementary and alternative medicines (CAM) containing pharmaceutical products (PP) [abstract 1150]. J Allergy Clin Immunol 2004;113:S313.

7. Wong HCG. The use of patent medicines in Canada - a tale of three cities [abstract P152]. Ann Allergy Asthma Immunol 2001;86:132.

8. Wong HCG. Potential adverse and allergic reaction to patent medicines containing prescription drugs. Allergy Clin Immunol Int: J World Allergy Org 2003;15:114-8.

9. Zhu Y-P. Chinese materia medica, chemistry, pharmacology, and applications. Amsterdam: Harwood Academic Publishers; 1998. p. 459-63.
10. Izzat MB, Yim APC, El-Zufari MH. A taste of Chinese medicine! Ann Thorac Surg 1998;66:941-2.

11. Cheng TO. Warfarin danshen interaction. Ann Thorac Surg 1999;67:894.

12. Yuan C-S, Wei G, Dey L, et al. American ginseng reduces warfarin's effect in health patients: a randomized, controlled trial. Ann Intern Med 2004;141:23-7.

13. Blumenthal M, Goldberg A, Brinckmann J, editors. Herbal medicine. Expanded Commission E monographs. Newton (MA): Integrative Medicine Communications; 2000. p. 233-9.

14. Peloso PM, Bailtie C. Hypertensive crisis with hua tansu. Ann R Coll Physicians Surg Can 2000;33:323.

15. Haller CA, Benowitz NL. Adverse cardiovascular and central nervous system events associated with dietary supplements containing ephedra alkaloids. N Engl J Med 2000;343:1833-8.

16. US Food and Drug Administration. Dietary supplements containing ephedrine alkaloids: proposed rule. Washington (DC): US Food and Drug Administration; 1997. Federal Register No.: 107:30677-30724. p. 62.

17. Health Canada requests recall of certain products containing ephedra/ephedrine January 9, 2002. Health Canada. Available at: http://www.hcsc.gc.ca (accessed February 2, 2002).

18. Dixon-Warren B. Annual reports of the Council of Health Promotion: Alternative Therapies and Allied Health Committee. In: British Columbia Medical Association. BCMA annual reports: 2001-2002. Vancouver, BC: British Columbia Medical Association; 2002. p. 31-2.

19. Yip LY, Zimmerman B. Mustard allergy: uncommon allergy with a common spice. Can J Allergy Immunol 1999;4:76-8.

20. Dietary Supplement Health and Education Act 1994, Pub. L. No. 103-407, Sec. 1 (a) 108 Stat. 4325 (October 25, 1994). p. 478-85. 